\title{
Obesity and associated type 2 diabetes and hypertension in factory workers of Bangladesh
}

\author{
Bishwajit Bhowmik ${ }^{*}$, Faria Afsana², Tareen Ahmed², Sadeka Akhter ${ }^{3}$, Hasan Ali Choudhury ${ }^{3}$, Anisur Rahman ${ }^{3}$, \\ Tofail Ahmed ${ }^{2}$, Hajera Mahtab² and A. K. Azad Khan ${ }^{2}$
}

\begin{abstract}
Background: Recent data suggest that the prevalence of obesity and its associate cardiometabolic risks are increasing in Bangladesh. Published data of obesity in Bangladeshi industry workers is scarce. The purpose of this study was to assess the prevalence of general and central obesity in Bangladeshi factory workers and their associations with diabetes and hypertension.

Methods: A total of 791 male factory workers aged $\geq 20$ years in capital Dhaka city of Bangladesh were investigated in a population-based cross-sectional survey. According to the International Association for the Study of Obesity and the International Obesity Task Force guidelines for Asian population, general obesity was defined as body mass index (BMI) $\geq 25 \mathrm{~kg} / \mathrm{m}^{2}$, central obesity was defined as a waist circumference (WC) of $\geq 90 \mathrm{~cm}$ and waist hip ratio (WHR) of $\geq 0.90$. Pearson's correlation coefficient and logistic regression analysis were used to observe the association between anthropometric indices (BMI, WC and WHR) and cardiometabolic risk indicators (FBG, 2hBG, SBP and DBP).
\end{abstract}

Results: The prevalence of overweight (BMI $23-24.9 \mathrm{~kg} / \mathrm{m}^{2}$ ) and general obesity $\left(\mathrm{BMI} \geq 25 \mathrm{~kg} / \mathrm{m}^{2}\right)$ in this study population was 29.8 and $43.5 \%$ respectively. Central obesity defined by WC and WHR was 35.3 and $78.3 \%$ respectively. Both general and central obesity were found to be significantly associated with diabetes and hypertension in separate logistic regression analyses.

Conclusion: The prevalence of general and central obesity in Bangladeshi factory workers was high, and it was associated with diabetes and hypertension.

Keywords: Obesity, Type 2 diabetes, Hypertension, Factory worker, Bangladesh

\section{Background}

The prevalence of obesity is increasing at an alarming rate worldwide [1,2]. Epidemiologic studies indicate that obesity is a major risk factor for cardiovascular disease, type 2 diabetes (DM), hypertension (HTN), cancer and premature death [2]. The high prevalence of obesity, combined with its concomitant cardiometabolic risks, makes it a global health challenge. Obesity is also increasing in Bangladesh. In 2010, World Health Organization (WHO)

\footnotetext{
*Correspondence: doctorbiplob@gmail.com

${ }^{1}$ Executive Diabetes care Centre, Diabetic Association of Bangladesh,

Dhaka, Bangladesh

Full list of author information is available at the end of the article
}

Risk Factor Survey estimated the prevalence of general obesity [Body mass index (BMI) $\geq 25 \mathrm{~kg} / \mathrm{m}^{2}$ ] in people over 15 was $11 \%$ and central obesity [waist circumference (WC): $\geq 94 \mathrm{~cm}$ in men and $\geq 80 \mathrm{~cm}$ in women] was $14 \%$ in Bangladesh [3]. Bangladesh Demographic and Health Survey (BDHS) 2011 reported $17 \%$ overweight or obesity $\left(\mathrm{BMI} \geq 25 \mathrm{~kg} / \mathrm{m}^{2}\right)$ in adult Bangladeshi population [4]. However, these studies used WHO cut-off levels for western population. A rural study assessed the prevalence of general (BMI $\geq 25 \mathrm{~kg} / \mathrm{m}^{2}$ ) and central obesity (WC: $\geq 90 \mathrm{~cm}$ in men and $\geq 80 \mathrm{~cm}$ in women) between 1999 and 2009 and reported increase trends of prevalence. Prevalence of general obesity increased from 4.6 to $27.3 \%$ and central obesity increased from 5.4 to $48.2 \%$ 
in 10 years [5]. Most importantly, studies in rural Bangladesh have also found a significant association between obesity and major cardiometabolic risk factors such as diabetes and hypertension [6]. These findings indicate the need of more information from different sociodemographic areas of our country for the development of public health strategies for its primary prevention and treatment.

Although Bangladesh is an agro-based country its industrial sector has shown a marked improvement over the last few decades. The industrial sector now contributes around $28.6 \%$ of the gross domestic product (GDP) but healthcare facilities for workers and employees are still inadequate in most of the industries in Bangladesh [7]. Studies conducted in USA [8], Australia [9], Italy [10] and India [11] have found increasing prevalence of obesity and other chronic diseases including diabetes, coronary artery disease and hypertension in industrial workers. Chronic diseases make those workers less productive, more prone to injury and have higher claim costs [8-10]. Therefore, if strategies are not developed to address this issue, there could be significant consequences for both employers and employees.

Considering the high prevalence of obesity and its relationship with diabetes and hypertension in our country, the "Diabetes Prevention Program in Work Places (DPWP)" study was conducted to assess the prevalence of general and central obesity in Bangladeshi factory workers and their associations with diabetes and hypertension.

\section{Methods}

The participants of this study were taken from the Diabetes Prevention Program in Work Places (DPWP), an ongoing diabetes prevention program of Diabetic Association of Bangladesh (BADAS). The main objective of this program is to establish a model surveillance system with special focus on diabetes for industry workers in Bangladesh. Program consists of screening of diabetes at work places and then organize education sessions about healthy lifestyle for all the participants. Individuals diagnosed with diabetes are referred to nearby BADAS centers for registration, treatment and further follow-ups. Furthermore, diagnosed prediabetes (impaired fasting glucose and or impaired glucose tolerance) individuals are invited for participate in diabetes prevention program of BADAS. In this study individuals were randomly selected from five industries (two pharmaceuticals, one tobacco, and two footwear industries) have already been enlisted in DPWP. To determine the required sample size, the formula: $\mathrm{n}=\mathrm{z}^{2} \mathrm{PQ} / \mathrm{d}^{2}$ was used, where $\mathrm{P}$ stands for prevalence (diabetes plus prediabetes) from a previous study [12], i.e. 0.165 (16.5 \%); $Q=1-$ P, i.e. 0.835 and $\mathrm{d}=$ allowable margin of error of known prevalence i.e. $0.025(2.5 \%)$. Thus the calculated sample size was, $\mathrm{n}=850$. One thousand individuals aged $\geq 20$ years of those 5 industries were invited to participate in this study by following simple random procedure. Of these, 870 (male 800 and female 70) agreed to participate. Response rate was $87 \%$. It should be noted that male are still dominating the labor market in Bangladesh except garments and textile industries. The study was conducted in between January 2011 to November 2013. The inclusion criteria were: $\geq 20$ years of age, have permanent job for more than 5 years, willing to participate, and being able to communicate. The exclusion criteria were: acute or chronic cardiac, renal or hepatic illness, and pregnancy at the time of screening. All potential participants received a letter inviting them to participate in the study. Written consent was obtained from each individual prior to inclusion. Study participants were also verbally informed of their right to withdraw from the study at any stage, or to omit their data from the analysis. In addition participants received a written copy of their rights during and following the completion of the study. The study protocol was approved by ethical review committee of Diabetic Association of Bangladesh for medical research.

Survey procedures included completing a questionnaire on socio-demographic information, anthropometric measurement, blood pressure measurement and measurement of both fasting blood glucose (FBG), and oral glucose tolerance test (OGTT). Anthropometric measurements, such as height, weight and waist and hip circumferences, were taken with the participants wearing light clothes and without shoes. BMI was calculated as the weight $(\mathrm{kg})$ divided by square of the height $\left(\mathrm{m}^{2}\right)$. Waist circumference (WC) was measured by placing a tape horizontally midway between the lower margin of the last palpable rib and iliac crest on the mid-axillary line. Hip circumference was measured at a level parallel to the floor, at the largest circumference of the buttocks. Waist hip ratio (WHR) was then calculated from waist and hip circumference $(\mathrm{cm})$. Blood pressure was measured in sitting position by aneroid sphygmomanometer on right hand, after a 10 min rest, and with standard procedure. A second reading was taken after 2 min resting interval. Mean of two measurements of blood pressure was used in the statistical analysis. Both fasting and 2-h blood glucose were measured using the portable glucometer (One Touch II, Lifescan, Milpitas, CA, USA) in whole blood obtained by finger prick in the middle finger-an approach that is widely used in resource-limited countries [4]. Blood glucose measurements were adjusted to obtain equivalent plasma glucose levels [13].

According to the International Association for the Study of Obesity and the International Obesity Task 
Force guidelines, overweight was defined as a BMI of $23.0-24.9 \mathrm{~kg} / \mathrm{m}^{2}$, while obesity was defined as BMI $\geq 25 \mathrm{~kg} / \mathrm{m}^{2}[14,15]$, central obesity was defined as a WC of $\geq 90 \mathrm{~cm}$ and waist hip ratio (WHR) of $\geq 0.90$. Diabetes was diagnosed if FBG value was $\geq 7.0 \mathrm{mmol} / \mathrm{l}$ and/or 2 - $\mathrm{h}$ post blood glucose was $\geq 11.1 \mathrm{mmol} / \mathrm{l}$ [16], self-reported T2DM, or use of diabetes medication. Hypertension (HTN) was defined as a systolic blood pressure (SBP) of $\geq 140 \mathrm{mmHg}$ and/or diastolic blood pressure (DBP) of $\geq 90 \mathrm{mmHg}$ [17] or if they were receiving treatment for HTN. Based on the monthly expenditure socio-economic condition was classified as low [ $<6000$ Bangladeshi Taka $(\mathrm{BDT}, 1 \mathrm{USD}=84 \mathrm{BDT})]$, medium $(6000-11,000 \mathrm{BDT})$ and high (>11,000 BDT). Education level was graded as illiterate: unable to read and write; undergraduate: having primary (from grades 1 to 5), secondary (from grades 6 to 10) and higher secondary education (from grades 11 to 12); graduate. Physical activity was graded on the ordinal scale of $1-3$, corresponding to light, moderate and heavy, according to the activity level based on their occupation. For the purpose of data analysis, these results were transformed into a binary variable-inactive (grade 1) and active (grade 2 and 3 ).

\section{Statistical analysis}

Due to limited number female participants $(\mathrm{n}=70)$, only 800 male data were considered for the analysis. The present analysis is based on 791 male for whom all the variables were available. Means and percentages with $95 \%$ confidence intervals adjusted for age were given for normally distributed continuous variables and categorical variables as needed. Age standardized prevalence by direct standardization method were estimated on the basis of 2001 census data before performing statistical tests [18]. Differences between the groups of means and proportions adjusted for age were tested by analysis of covariance (ANCOVA) and logistic regression. Measures of association between anthropometric indices (BMI, WC and WHR) and cardiometabolic variables (SBP, DBP, FBG and 2hBG) were tested by Pearson's correlation coefficient. In logistic regression analyses controlling by age, was assessed between (a) general obesity and (b) central obesity (WC and WHR) as categorical independent variables and, taken one by one, diabetes and hypertension as dependent variables. Both STATA 11 for Windows (STATA Co., College Station, TX, USA) and PASW statistics version 21 for Windows (SPSS Inc., Chicago, IL, USA) were used as needed. A p value $<0.05$ was considered statistically significant.

\section{Results}

Basic characteristics of the study population are shown in Table 1. Among the total number of participants,
Table 1 Basic characteristics of the study population (n= 791)

\begin{tabular}{|c|c|}
\hline Variable & $\begin{array}{l}\text { Mean/percentage } \\
(95 \% \mathrm{Cl})\end{array}$ \\
\hline Age $\left(\right.$ year) ${ }^{\mathrm{a}}$ & $38.9(38.3,39.6)$ \\
\hline Weight in $\mathrm{kg}^{\mathrm{a}}$ & $68.2(67.5,68.9)$ \\
\hline High socio-economic status ${ }^{b}$ & $19.0(16.3,21.7)$ \\
\hline Higher education ${ }^{\mathrm{b}}$ & $18.8(16.1,21.4)$ \\
\hline Physical inactivity ${ }^{b}$ & $35.9(32.6,39.1)$ \\
\hline Family history of diabetes $^{b}$ & $38.9(35.5,42.3)$ \\
\hline Family history of hypertension ${ }^{b}$ & $15.9(13.5,18.6)$ \\
\hline Diabetes $^{b}$ & $15.4(12.9,17.9)$ \\
\hline Hypertension ${ }^{b}$ & $27.9(24.8,31.1)$ \\
\hline
\end{tabular}

the mean age and weight of the study population was 38.3 years and $68.2 \mathrm{~kg}$ respectively. Nineteen percent $(19.0 \%)$ of study participants were of high socio-economic status, $18.8 \%$ had higher education and $35.9 \%$ were physically inactive. Among the participants, 38.9 and $15.9 \%$ had family history diabetes and hypertension and 15.4 and $27.9 \%$ had diabetes and hypertension respectively.

Mean BMI and the prevalence of overweight and obesity by age are shown in Table 2. Age adjusted mean of overall BMI was $24.5 \mathrm{~kg} / \mathrm{m}^{2}$. The age standardized prevalence of overweight and obese were 29.8 , and $43.7 \%$, respectively.

Mean of WC and WHR and the prevalence of central obesity by age are shown in Table 3 . The age adjusted mean of central obesity based on WC and WHR were $86.6 \mathrm{~cm}$ and 0.93 respectively. There was no significant mean difference observed between the age groups. The age standardized prevalence of central obesity based on WC and WHR were 35.3 and $78.3 \%$ respectively.

Cardiometabolic risk factors in both general and central obesity by WC and WHR are shown in Table 4. All the cardiometabolic risk parameters including blood pressure and glycemic parameters were comparable between all three groups. Higher rate of DM was observed in both general and central obesity groups and higher rate of HTN was only observed in central (define by both WC and WHR) obesity groups.

Correlation between BMI, WC and WHR and cardiometabolic risk factors are presented in Table 5. A significant positive correlation was seen in between BMI, WC and WHR with SBP, DBP, FBG and 2hBG.

Table 6 shows the odds ratio of DM and HTN for general obesity by BMI and central obesity by WC and WHR after adjusted for age. WC and WHR were significantly 
Table 2 Mean body mass index (BMI) and the prevalence of overweight $\left(23-24.9 \mathrm{~kg} / \mathrm{m}^{2}\right)$ and obesity $\left(\geq 25 \mathrm{~kg} / \mathrm{m}^{2}\right)$ by age

\begin{tabular}{lllll}
\hline $\begin{array}{l}\text { Age group } \\
\text { (years) }\end{array}$ & Number & $\begin{array}{l}\text { BMI } \\
\text { Mean } \\
(\mathbf{9 5} \% \mathbf{C l})\end{array}$ & $\begin{array}{l}\text { Overweight } \\
\%(\mathbf{9 5} \% \mathrm{Cl})\end{array}$ & $\begin{array}{l}\text { Obese } \\
\%(\mathbf{9 5} \% \mathrm{Cl})\end{array}$ \\
\hline Men & & & & \\
$20-30$ & 178 & $23.6(23.1,24.1)$ & $27.5(20.9,34.1)$ & $30.9(24.1,37.7)$ \\
$31-40$ & 246 & $25.2(24.8,25.6)$ & $28.5(22.8,34.1)$ & $52.0(45.8,58.3)$ \\
$41-50$ & 292 & $25.0(24.7,25.4)$ & $32.2(26.8,37.6)$ & $45.5(39.8,52.3)$ \\
$\geq 51$ & 75 & $24.8(23.9,25.6)$ & $30.7(20.1,41.2)$ & $40.0(28.8,51.1)$ \\
\hline $\begin{array}{c}\text { Age } \\
\text { adjusted }\end{array}$ & 791 & $24.5(22.2,22.4)$ & $29.8(26.7,33.0)$ & $43.7(40.3,47.2)$ \\
\hline
\end{tabular}

Values are presented as mean (95\% confidence interval) or $\%$ (95\% confidence interval) adjusted for age as indicated

$\mathrm{Cl}$ confidence interval associated with both DM and HTN. However, BMI was only significantly associated with DM only. WHR was the most sensitive index for diabetes (OR $3.90 \mathrm{p}<0.001)$ and HTN (OR 1.80 for male $\mathrm{p}<0.021$ ).

\section{Discussion}

This is the first population-based study to explore the prevalence of general and central obesity among factory workers in Bangladesh and their association with DM and HTN. In this study, mean BMI was $24.5 \mathrm{~g} / \mathrm{m}^{2}$ and age standardized prevalence of overweight and obesity were 35.3 and $78.3 \%$ respectively. The findings in this study were higher from the previous studies conducted in both urban and rural Bangladeshi population [6, 19, 20]. Our study findings were also higher than studies conducted in Indian factory workers $[11,21]$. However, they used

Table 3 Mean of waist (WC) and waist hip ratio (WHR) and the prevalence of central obesity by age

\begin{tabular}{|c|c|c|c|c|c|c|}
\hline \multirow{2}{*}{$\begin{array}{l}\text { Age group } \\
\text { (years) }\end{array}$} & \multicolumn{3}{|l|}{ WC } & \multicolumn{3}{|l|}{ WHR } \\
\hline & Number & Mean $(95 \% \mathrm{Cl})$ & $\begin{array}{l}\text { Central obesity by } \\
\text { WC }(95 \% \mathrm{Cl})\end{array}$ & Number & Mean $(95 \% \mathrm{Cl})$ & $\begin{array}{l}\text { Central obesity by } \\
\text { WHR }(95 \% \mathrm{Cl})\end{array}$ \\
\hline \multicolumn{7}{|l|}{ Men } \\
\hline $20-30$ & 178 & $85.1(82.8,87.3)$ & $24.9(12.1,37.7)$ & 178 & $0.91(0.89,0.93)$ & $78.6(70.5,86.8)$ \\
\hline $31-40$ & 246 & $88.0(86.9,89.2)$ & $32.9(25.7,40.1)$ & 246 & $0.94(0.93,0.94)$ & $83.3(78.9,87.8)$ \\
\hline $41-50$ & 292 & $87.5(86.2,88.9)$ & $42.6(33.9,51.2)$ & 292 & $0.94(0.93,0.95)$ & $73.1(60.2,85.9)$ \\
\hline$\geq 51$ & 75 & $85.8(82.7,88.9)$ & $34.9(16.4,53.6)$ & 75 & $0.93(0.91,0.95)$ & $45.7(22.1,69.2)$ \\
\hline Age adjusted & 791 & $86.6(85.9,87.3)$ & $35.3(32.0,38.5)$ & 791 & $0.93(0.92,0.94)$ & $78.3(75.4,81.2)$ \\
\hline
\end{tabular}

Central obesity by WC: $(\geq 90 \mathrm{~cm})$; central obesity by WHR: $(\geq 0.90)$. Values are presented as mean (confidence interval) or $\%$ (95\% confidence interval) adjusted for age as indicated

Cl confidence interval

Table 4 Differences in cardiometabolic risk factors based on general obesity, central obesity by WC and central obesity by WHR

\begin{tabular}{|c|c|c|c|c|c|c|}
\hline \multirow{2}{*}{$\begin{array}{l}\text { Cardiometabolic } \\
\text { factor }\end{array}$} & \multicolumn{2}{|c|}{ General obesity by BMI } & \multicolumn{2}{|c|}{ Central obesity by WC } & \multicolumn{2}{|c|}{ Central obesity by WHR } \\
\hline & $\begin{array}{l}\text { Non-obese } \\
<25 \mathrm{~kg} / \mathrm{m}^{2}\end{array}$ & $\begin{array}{l}\text { Obese } \geq \\
25 \mathrm{~kg} / \mathrm{m}^{2}\end{array}$ & $\begin{array}{l}\text { Non-obese } \\
<90 \mathrm{~cm}\end{array}$ & Obese $\geq 90 \mathrm{~cm}$ & Non-obese $<0.90$ & Obese $\geq 0.90$ \\
\hline $\mathrm{SBP}(\mathrm{mmHg})$ & $117.3(115.8,118.7)$ & $121.9(120.3,123.4)^{*}$ & $118.3(116.9,119.6)$ & $\begin{array}{l}122.3(120.6 \\
124.0)^{*}\end{array}$ & $114.9(112.4,117.5)$ & $120.3(119.0,121.6)^{*}$ \\
\hline $\mathrm{DBP}(\mathrm{mmHg})$ & $78.8(77.9,79.6)$ & $81.7(80.8,82.6)^{*}$ & $79.1(78.4,79.9)$ & $82.2(81.1,83.2)^{*}$ & $76.9(75.4,78.4)$ & $80.5(80.1,81.6)^{*}$ \\
\hline HTN, \% & $25.4(21.5,29.2)$ & $29.7(25.0,34.5)$ & $24.5(20.8,28.1)$ & $33.4(27.9,38.8)^{*}$ & $19.2(12.4,26.1)$ & $30.2(26.3,34.1)^{*}$ \\
\hline $\mathrm{FBG}(\mathrm{mmol} / \mathrm{L})$ & $5.8(5.7,5.9)$ & $6.0(5.8,6.2)^{*}$ & $5.8(5.7,5.9)$ & $6.1(5.9,6.3)^{*}$ & $5.6(5.4,5.9)$ & $6.1(6.0,6.3)^{*}$ \\
\hline $2 \mathrm{hBG}(\mathrm{mmol} / \mathrm{L})$ & $7.8(7.5,8.0)$ & $8.0(7.7,8.4)$ & $7.7(7.4,8.0)$ & $8.3(7.9,8.7)^{*}$ & $7.2(6.7,7.7)$ & $8.4(8.1,8.7)^{*}$ \\
\hline $\mathrm{DM}, \%$ & $11.6(8.7,14.4)$ & $19.2(15.1,23.25)^{*}$ & $10.7(8.0,13.4)$ & $22.6(178,27.4)^{*}$ & $5.5(1.5,9.5)$ & $20.3(16.8,23.9)^{*}$ \\
\hline
\end{tabular}

Values are presented as mean (95\% confidence interval) or \% (95 \% confidence interval) adjusted for age as indicated. $\mathrm{P}<0.05$

* $\mathrm{P}<0.05$ between non-obese and obese in the same group

$B M I$ body mass index, WC waist circumference, WHR waist hip ratio, SBP systolic blood pressure, DBP diastolic blood pressure, HTN hypertension, $F P G$ fasting plasma glucose, $2 h P G 2 \mathrm{~h}$ plasma glucose 
Table 5 Correlation (r) analysis of body mass index (BMI), waist circumference (WC) and waist hip ratio (WHR) with cardiometabolic risk factors

\begin{tabular}{|c|c|c|c|c|c|c|}
\hline \multirow[t]{2}{*}{ Variables } & \multicolumn{2}{|l|}{ BMI } & \multicolumn{2}{|l|}{ WC } & \multicolumn{2}{|l|}{ WHR } \\
\hline & $r$ & $P$ value & $r$ & $P$ value & $r$ & $P$ value \\
\hline \multicolumn{7}{|l|}{ Men } \\
\hline SBP & 0.217 & $<0.001$ & 0.254 & $<0.001$ & 0.214 & $<0.001$ \\
\hline $\mathrm{DBP}$ & 0.238 & $<0.001$ & 0.296 & $<0.001$ & 0.231 & $<0.001$ \\
\hline FBG & 0.197 & $<0.001$ & 0.207 & $<0.001$ & 0.270 & $<0.001$ \\
\hline $2 \mathrm{hBG}$ & 0.134 & 0.001 & 0.171 & $<0.001$ & 0.287 & $<0.001$ \\
\hline
\end{tabular}

SBP systolic blood pressure, DBP diastolic blood pressure, FPG fasting plasma glucose, $2 h P G 2 \mathrm{~h}$ plasma glucose

Table 6 Adjusted odds ratio (OR) of diabetes (DM) and hypertension (HTN) for general obesity (BMI $\left.\geq 25 \mathrm{~kg} / \mathrm{m}^{2}\right)$, central obesity by WC $(\geq 90 \mathrm{~cm})$ and central obesity by WHR $(\geq 0.90)$

\begin{tabular}{|c|c|c|c|c|c|c|}
\hline & \multicolumn{2}{|c|}{ General obesity by BMI } & \multicolumn{2}{|c|}{ Central Obesity by WC } & \multicolumn{2}{|c|}{ Central Obesity by WHR } \\
\hline & OR (95 \% Cl) & $P$ value & OR (95 \% Cl) & P value & OR (95 \% Cl) & $P$ value \\
\hline \multicolumn{7}{|l|}{ Men } \\
\hline $\mathrm{DM}$ & $1.70(1.14,2.52)$ & 0.008 & $2.39(1.61,3.57)$ & $<0.001$ & $3.90(1.76,8.73)$ & 0.001 \\
\hline HTN & $1.18(0.86,1.62)$ & 0.304 & $1.54(1.11,2.14)$ & 0.009 & $1.80(1.10,2.99)$ & 0.021 \\
\hline
\end{tabular}

Adjusted odds ratio after logistic regression analysis adjusted for age

$B M I$ body mass index, WC waist circumference, WHR waist hip ratio, $\mathrm{Cl}$ confidence interval

different cut-off levels to define overweight and obesity. In addition, place of study and study participants were also different from our study participants. Age adjusted mean based on WC and WHR were $86.6 \mathrm{~cm}$ and 0.93 and age standardized prevalence of central obesity based on WC and WHR were 35.3, and $78.3 \%$ respectively for the study population. The findings of the study were consistent with the studies conducted in both northern and Southern Indian workers $[11,21]$.

The prevalence of central obesity was higher than general obesity in our study which indicate a significant portion of the population may not be classified as obese by BMI levels. These study findings are consistent with previous rural Bangladeshi study [6]. Hence, it has been suggested that a single BMI cut-off level for both male and female might not be adequate to define general obesity. Sex and ethnic specific BMI levels for defining general obesity might be preferable. In our study, the highest prevalence of both general and central obesity was observed in the middle-aged (30-50 years) group which is consistent with our previous rural studies $[5,6$, 12]. Age related change, i.e., secretion of male hormone testosterone could be the underline cause of our finding. Higher rate of DM and HTN was observed in both general and central obesity groups in our study. Prevalence of these risk factors increased during the most productive years putting them at risk of cardiovascular morbidity and mortality at relatively younger age.

We have found a significant but weak association (correlation) between obesity indices (BMI, WC and WHR) and cardiometabolic risk factors including SBP, DBP, FBG, and 2hBG. However, significant associations were identified for the dichotomized variable (odds ratios). Size of the sample and underline confounding effects could be the key factors but need more in-depth study including all the possible influences to confirm the above mentioned findings.

In our study, we have found that the indices of central obesity (WC and WHR) were more closely associated with DM than general obesity (BMI). However, no significant difference were observed between general and central obesity indices for predicting HTN. In the present study, WHR was the most sensitive risk indicator of DM and HTN which is in agreement with studies conducted in different Asian and as well as in Bangladeshi populations [6, 22-25]. From a pathophysiological point of view, central obesity has been found to play a vital role in the pathogenesis of insulin resistance, which is a key factor leading to the development of DM and HTN.

Limitations of the study are that this was a cross-sectional study. Therefore, the association between diabetes, HTN and obesity cannot be clearly established. As 
the study was carried out in an industrial setting, it may not be representative of the general population. However, this study is broadly generalizable to similar large, organized sector workforce in Bangladesh. Further, our study population comprised only men. The results of this study cannot be generalized to women, in whom the risk factor as well as disease burden could be different than that reported in this study population. Our study has several strengths including high response rate $(87 \%)$, followed by simple random procedure for sample collection, and use of highly trained interviewers to ensure the quality of the data collection.

\section{Conclusion}

Our study findings documented that the prevalence of both general and central obesity in adult Bangladeshi factory workers is high, and both the obesity indices were associated with DM and HTN. So the high prevalence of non-communicable disease risk factors including obesity, DM and HTN in Bangladeshi industrial settings as a cause of concern as well as an opportunity for carrying out work place interventions. This industry workers provided an opportunity to study the influence of socioeconomic and lifestyle transition on the prevalence of obesity and associated DM and HTN. Furthermore, we need well design longitudinal studies to confirm our findings. Our results support the need for periodic low-cost screening programs as well as awareness program about healthy lifestyle for the employees. In addition, we also recommended periodic follow-ups of the employees with DM and HTN.

\section{Authors' contributions}

$\mathrm{BB}$ and TA designed the protocol, carried out the field work, performed the data analysis, and drafted the manuscript. FA, TA, SA, HA and AR participated in data collection and drafting the manuscript. HM and AKAK participated in the design of the study and edited the manuscript. All authors read and approved the final manuscript.

\section{Author details \\ ${ }^{1}$ Executive Diabetes care Centre, Diabetic Association of Bangladesh, Dhaka, Bangladesh. ${ }^{2}$ Department of Endocrinology, Bangladesh Institutes of Research and Rehabilitation of Diabetes, Endocrine and Metabolic Disorders (BIRDEM), Dhaka, Bangladesh. ${ }^{3}$ Diabetes Prevention Program in Work Places, Diabetic Association of Bangladesh, Dhaka, Bangladesh.}

\section{Acknowledgements}

We acknowledge the contribution of our survey team members and volunteers for their continuous effort in the collection of data. We are grateful to all participants in the study for their active co-operation. We express our admiration to the authority of Diabetic Association of Bangladesh for funding and all the logistic support. We also express our appreciation to the management of the factories for their cooperation and support.

\section{Compliance with ethical guidelines}

\section{Competing interests}

The authors declare that they have no competing interests.
Received: 5 September 2014 Accepted: 24 August 2015

Published online: 19 September 2015

\section{References}

1. Abelson P, Kennedy D. The obesity epidemic. Science. 2004;304:1413.

2. Haslam D, James P. Obesity. Lancet. 2005;366:1197-209.

3. Non-communicable disease risk factor survey, Bangladesh 2010. World Health Organization 2011. http://www.searo.who.int/bangladesh/.../ ncd_risk_ractor_survey_report_ban_2. Last accessed June 2014.

4. National Institute of Population Research and Training (NIPORT), Mitra and Associates, and ICF International. Bangladesh Demographic and Health Survey 2011. Dhaka: NIPORT, Mitra and Associates, and ICF International; 2013.

5. Bhowmik B, Afsana F, Diep LM, Munir SB, Wright E, Mahmood S, Khan AKA, Hussain A. Increasing prevalence of type 2 diabetes in a rural Bangladeshi population: a population based study for 10 years. Diabetes Metab J. 2013;37:46-53.

6. Bhowmik B, Munir SB, Diep LM, Siddiquee T, Habib SH, Samad MA, Khan AKA, Hussain A. Anthropometric indicators of obesity for identifying cardiometabolic risk factors in a rural Bangladeshi population. J Diabetes Invest. 2013;4:361-8.

7. Bangladesh Bureau of Statistics. Statistical Pocketbook of Bangladesh 2010: Bangladesh Bureau of Statistics, Statistical Division, Ministry of Planning, Government of the People's Republic of Bangladesh. 2010.

8. Luckhaupt SE, Cohen MA, Li J, Calvert GM. Prevalence of obesity among U.S. workers and associations with occupational factors. Am J Prev Med. 2014;46:237-48

9. Overweight and obesity. Implications for workplace health and safety and workers' compensation-scoping paper. Commonwealth of Australia 2007: Attorney-General's Department, Robert Garran Offices, National Circuit, Barton ACT 2600.

10. Di Lorenzo L, De Pergola G, Zocchetti C, LAbbate N, Basso A, Pannacciulli N, Cignarelli M, Giorgino R, Soleo L. Effect of shift work on body mass index: results of a study performed in 319 glucose-tolerant men working in a Southern Italian industry. Int J Obes Relat Metab Disord. 2003;27:1353-8.

11. Prabhakaran D, Shah P, Chaturvedi V, Ramakrishnan L, Manhapra A, Reddy KS. Cardiovascular risk factor prevalence among men in a large industry of northern India. Natl Med J India. 2005;18:59-65.

12. Bhowmik B, Munir SB, Hossain IA, et al. Prevalence of Type 2 Diabetes and Impaired Glucose Regulation with Associated Cardiometabolic Risk Factors and Depression in an Urbanizing Rural Community in Bangladesh: a Population-Based Cross- Sectional Study. Diabetes Metab J. 2012;36:422-32.

13. D'Orazio P, Burnett RW, Fogh-Andersen N, Jacobs E, Kuwa K, Külpmann $W R$, et al. International Federation of Clinical Chemistry Scientific Division Working Group on Selective Electrodes and Point of Care Testing. Approved IFCC recommendation on reporting results for blood glucose (abbreviated). Clin Chem. 2005;51:1573-6.

14. Choo V. WHO reassesses appropriate body-mass index for Asian populations. Lancet. 2002;360:235.

15. World Health Organization, Western Pacific Region. The International Association for the Study of Obesity and the International Obesity Task Force. The Asia-Pacific perspective: redefining obesity and its treatment. Sydney, Australia: Health Communications Australia Pty Limited; 2000. Available: http://www.diabetes.com.au/pdf/obesity_report.pdf. Accessed 2006 Aug 23.

16. World Health Organization (WHO). Definition and diagnosis of diabetes mellitus and intermediate hyperglycemia: Report of a WHO/IDF Consultation. Geneva: WHO; 2006.

17. WHO International Society of Hypertension. Guidelines for the management of hypertension. Guidelines subcommittee. J Hypertens. 1999;17:151-83

18. Bangladesh Bureau of Statistics. Statistical pocket book of Bangladesh. Dacca: Statistical Division, Ministry of Planning; 2001.

19. Kelly T, Yang W, Chen CS, Reynolds K, He J. Global burden of obesity in 2005 and projections to 2030. Int J Obes (Lond). 2008;32:1431-7. 
20. Saquib N, Khanam MA, Saquib J, Anand S, Chertow GM, Barry M, Ahmed T, Cullen MR. High prevalence of type 2 diabetes among the urban middle class in Bangladesh. BMC Public Health. 2013;31(13):1032.

21. Kaur P, Rao TV, Sankarasubbaiyan S, Narayanan AM, Ezhil R, Rao SR, Gupte MD. Prevalence and distribution of cardiovascular risk factors in an urban industrial population in south India: a cross-sectional study. J Assoc Physicians India. 2007:55:771-6.

22. Pua $\mathrm{YH}$, Ong PH. Anthropometric indices as screening tools for cardiovascular risk factors in Singaporean women. Asia Pac J Clin Nutr. 2005; 14:74-9.

23. Hayashi T, Boyko EJ, McNeely MJ, et al. Minimum waist and visceral fat values for identifying Japanese Americans at risk for the metabolic syndrome. Diabetes Care. 2007:30:120-7.
24. Dalton M, Cameron AJ, Zimmet PZ, et al. AusDiab Steering Committee Waist circumference, waist-hip ratio and body mass index and their correlation with cardiovascular disease risk factors in Australian adults. J Intern Med. 2003:254:555-63.

25. Sayeed MA, Mahtab H, Azad Khan AK, et al. Waist-to-height is a better obesity index than body mass index and waist to- hip ratio for predicting diabetes, hypertension and lipidemia. Bangladesh Med Res Counc Bull. 2003;29:1-10

\section{Submit your next manuscript to BioMed Central} and take full advantage of:

- Convenient online submission

- Thorough peer review

- No space constraints or color figure charges

- Immediate publication on acceptance

- Inclusion in PubMed, CAS, Scopus and Google Scholar

- Research which is freely available for redistribution

Submit your manuscript at

www.biomedcentral.com/submit

C Biomed Central 